\title{
Pseudomonas cepacia in cystic fibrosis
}

Pseudomonas cepacia, a Gram negative bacillus first described as a cause of soft rot in onions, is now recognised as an important opportunistic pathogen in altered hosts. ${ }^{1} \mathrm{~A}$ distant relation of Pseudomonas aeruginosa, it is ubiquitous in the environment and frequently found in association with soil, water, and plants. It is a hardy organism, able to multiply in distilled water and survive in many medical disinfectants. Although virtually non-pathogenic in healthy individuals, those with altered defences have experienced infections of endocardium, blood, peritoneum, bone, joint, meninges, and lung. ${ }^{1}$ The organism is inherently resistant to many antimicrobial drugs, making effective treatment difficult.

The first report of Ps cepacia infection in patients with cystic fibrosis came from Philadelphia, USA in $1977 ;^{2}$ at this early stage an association with an adverse outcome for some of those infected was noted. A report of the isolation of Ps cepacia from patients with cystic fibrosis on the west coast of the USA was published in $1979 .{ }^{3}$ By 1982 carriage rates of $45 \%$ were reported from one Canadian clinic, ${ }^{4}$ and in 1983 the same centre recognised a rapidly fatal outcome in a proportion of those who harboured the organism. ${ }^{5}$ Further work in this centre in 1985 confirmed the increased risk of death following acquisition of Ps cepacia in a case-control format. ${ }^{6}$ In the same year workers in Cleveland, Ohio described a range of responses to this infection - no change in clinical status, an increased rate of decline of lung function, or rapid progression to death the latter being seen in $40 \%$ of their patients. ${ }^{7}$

The first report of the death of a patient with cystic fibrosis thought to be attributable to Ps cepacia infection in the UK appeared from Scotland in $1986 .{ }^{8}$ Four years later the first sizeable series was published from Leeds. ${ }^{9}$ Workers at this centre noted an increase in the prevalence of Ps cepacia infection from $1 \%$ to $8 \%$ over a six year period (1984-9) with a peak prevalence of $10 \%$ amongst 139 patients in 1988; they also commented on an adverse outcome for a proportion of those infected. In 1988 a lower prevalence of $4 \cdot 1-5 \cdot 9 \%$ was found in an adult cystic fibrosis clinic in London, ${ }^{10}$ and in 1991 a $7 \%$ prevalence of $P s$ cepacia infection was reported from a paediatric centre in Manchester. ${ }^{11}$

In the USA attempts to investigate the epidemiology of this new pathogen in the cystic fibrosis field had focused on the possibility of patient-to-patient transmission, spurred on by the observation of a relatively high concordance for Ps cepacia infection amongst siblings. ${ }^{67}$ Attention was initially concentrated on the hospital environment and, although early endeavours to demonstrate contamination of the immediate environment were not fruitful, ${ }^{12}$ associations were found between periods of hospitalisation and the acquisition of Ps cepacia infection. Some physicians in the USA adopted a policy of hospital segregation of Ps cepacia infected patients from those without the infection and demonstrated a reduction in new Ps cepacia infections. ${ }^{13}$ Such policies were extended to cover summer camps where large numbers of patients mixed outside the hospital environment. These measures, however, were not seen as appropriate by all and caused considerable controversy both amongst physicians and the patients themselves. ${ }^{14}$ Subsequent introduction of methods of strain identification that used genotypic characteristics to investigate transmission of Ps cepacia streng- thened the case for person-to-person transmission. ${ }^{1516}$

In Birmingham, UK, prompted by the American literature and our own experience of the sudden and unexpected death of a patient who acquired $P s$ cepacia infection, we had been following a segregation policy within the hospital and during summer camps since 1988 for a small number of adults with Ps cepacia infection. Despite these measures, in 1991 we experienced an outbreak of new Ps cepacia infections in patients attending our centre with the prevalence of this infection rising to $8.3 \%$. Genotype analysis of the strains involved in the outbreak, together with enquiry into social contacts outside the hospital environment, led us to believe that, not only was personto-person transmission important, but that this could occur during social contacts in the cystic fibrosis community. ${ }^{17}$ We advised that social contacts between patients with and without Ps cepacia infection should be kept to a minimum, accepting that this advice was both difficult to give and to receive. A segregation policy was instituted at the 3rd National Conference of the Adult Cystic Fibrosis Association (ACFA) held in Birmingham in 1991, advising against the sharing of sleeping accommodation by patients with and without Ps cepacia. The adoption of these policies met with disquiet from some of our colleagues at other centres, but it has been followed by a sharp reduction in new infections in our own centre with only one in the last year.

Increasing numbers of cystic fibrosis centres in the UK have experienced similar outbreaks of new Ps cepacia infections. Investigations of outbreaks in Edinburgh and Manchester, ${ }^{18}$ Cardiff, ${ }^{19}$ and, most recently, Liverpool ${ }^{20}$ support the notion of the importance of patient-to-patient transmission in the spread of this infection in cystic fibrosis communities. A developing theme in these enquiries and those from the USA is the importance of patient contact outside the hospital environment, either in organised gatherings such as those of the various patient support groups or in private social contacts which frequently develop between cystic fibrosis patients. We and others believe that, for gregarious individuals, these social contacts probably represent a greater risk for acquisition of $P s$ cepacia infection in Ps cepacia negative patients than hospitalisation in a unit where segregation policies are in place. $^{21}$

Others remain unconvinced of the pathogenicity and transmissibility of this organism. A carefully performed controlled study from a paediatric cystic fibrosis centre in Manchester, whilst not excluding the possibility of cross infection, found the introduction of segregation regrettable. ${ }^{22}$ A study from the UK's largest cystic fibrosis centre at the Royal Brompton Hospital found no evidence for patient-to-patient transmission although the authors accepted that nosocomial acquisition may have occurred. The Brompton patient group differs from that seen at most adult cystic fibrosis centres in that it is drawn from a much wider geographical base including overseas patients. The opportunity for social interactions outside hospital amongst these patients may therefore be less than in other centres. Indeed, it seems to be the case that the recent outbreaks of new Ps cepacia infections have occurred in centres whose patients participate in the most active social networks. ${ }^{182021}$

There is mounting evidence that some strains of $P s$ 
cepacia may be more transmissible and perhaps more pathogenic than others. In most of the reported UK outbreaks individual strains have been responsible for a large proportion of new infections within centres. Moreover, an individual strain has been implicated in outbreaks which may have occurred in several different centres supporting the notion of the importance of transmission occurring at regional, national, and perhaps international gatherings. ${ }^{18}$ Evidence that $P s$ cepacia may act as more than an innocent bystander in those patients who experience an adverse outcome is seen from the high incidence of septicaemia as a terminal event in these patients. This has been a particular problem in patients with Ps cepacia infection undergoing transplantation and is in sharp distinction to patients colonised with Ps aeruginosa in whom septicaemia is rare.

The current majority view is that, for a proportion of patients with cystic fibrosis, acquisition of Ps cepacia infection carries real risks of deterioration or premature death. Measures aimed at reducing acquisition, including segregation within the hospital environment and reduction of social contacts without, should be supported. These views are supported by guidelines from the ACFA ${ }^{23}$ and a recent European symposium. ${ }^{24}$ Acceptance and institution of these measures are not without their difficulties, and these issues were sensitively dealt with in a recent editorial. ${ }^{25}$

Lastly, recognition of the existence of a problem has been hampered in some centres by failure to identify $P s$ cepacia in sputum specimens. Special laboratory techniques are required, especially if $P s$ cepacia infection coexists with $P s$ aeruginosa which rapidly overgrows $P s$ cepacia on non-inhibitory media. For many laboratories in the UK, especially those dealing with small numbers of cystic fibrosis specimens, these techniques may not be in regular use. Every physician dealing with cystic fibrosis patients should ensure the competence of their laboratory to isolate this pathogen. ${ }^{26}$ Universal and reliable recognition of the infection when present, together with common sense measures adopted to reduce transmission of this organism, should result in reduction of further spread and cessation of an epidemic which could yet cause further deaths amongst patients with cystic fibrosis.

Reprint requests to: Dr D Stableforth.

Adult Cystic Fibrosis Unit, Birmingham Heartlands Hospital,

DAVID E STABLEFORTH

Bordesley Green East,

Birmingham B9 5ST, UK

Department of Respiratory Medicine,

Chelsea and Westminster Hospital,

DAVID L SMITH
1 Goldmann DA, Klinger J. Pseudomonas cepacia: biology, mechanisms of virulence, epidemiology. F Pediatr 1986;108:806-12.

2 Laraya-Cuasay LR, Lipstein M, Huang NN. Pseudomonas cepacia in the respiratory flora of patients with cystic fibrosis. Pediatr Res 1977;11:502.

3 Blessing J, Walker J, Maybury B, Yeager AS, Lewiston N. Pseudomonas cepacia and maltophilia in the cystic fibrosis patient. Am Rev Respir Dis 1979;119:262.

4 Nolan G, McIvor P, Levison H, Fleming PC, Corey M, Gold R. Antibiotic prophylaxis in cystic fibrosis: inhaled cephaloridine as an adjunct to oral cloxacillin. F Pediatr 1982;101:626-30.

5 Gold R, Jin E, Levison H, Isles A, Fleming PC. Ceftazidime alone and in combination in patients with cystic fibrosis: lack of efficacy in treatment of severe respiratory infections caused by Pseudomonas cepacia. $\mathcal{f}$ Antimicrob Chemother 1983;12(Suppl. A):331-6.

6 Tablan OC, Chorba TL, Schidlow DV, White JW, Hardy KA, Gilligan $\mathrm{PH}$, et al. Pseudomonas cepacia colonisation in patients with cystic fibrosis: risk factors and clinical outcome. $\mathcal{F}$ Pediatr 1985;107:382-7.

7 Thomassen MJ, Demko CA, Klinger JD, Stern RC. Pseudomonas cepacia colonization amongst patients with cystic fibrosis. Am Rev Respir Dis 1985;131:791-6.

8 Glass S, Govan JRW. Pseudomonas cepacia - fatal pulmonary infection in a patient with cystic fibrosis. $\mathcal{F}$ Infect 1986;13:157-8.

9 Simmonds EJ, Conway SP, Ghoneim ATM, Ross H, Littlewood JM Pseudomonas cepacia: a new pathogen in patients with cystic fibrosis referred to a large centre in the United Kingdom. Arch Dis Child 1990;65:874-7.

10 Taylor RF, Dalla Costa L, Kaufmann ME, Pitt TL, Hodson ME. Pseudomonas cepacia pulmonary infection in adults with cystic fibrosis: is nosocomial acquisition occurring? F Hosp Infect 1992;21:199-204.

11 Gladman G, Conner PJ, Williams RF, David TJ. Controlled study of Pseudomonas cepacia and Pseudomonas maltophilia in cystic fibrosis. Arch Dis Child 1992;67:192-5.

12 Hardy KA, McGowan KL, Fisher MC, Schidlow DV. Pseudomonas cepacia in the hospital setting: lack of transmission between cystic fibrosis in the hospital setting: lack of

13 Thomassen MJ, Demko CA, Doershuk CF, Stern RC, Klinger JD. Pseudomonas cepacia: decrease in colonisation in patients with cystic fibrosis. Am Rev Respir Dis 1986;134:669-71.

14 Speert DP, Davidson AGF, Wong LTK. Communicability of Pseudomona infections in patients with cystic fibrosis. F Pediatr 1989;114:1068-9.

15 LiPuma JJ, Dasen SE, Nielson DW, Stern RC, Stull TL. Person-to-person transmission of Pseudomonas cepacia between patients with cystic fibrosis Lancet 1990;336:1094-6.

16 LiPuma JJ, Mortensen JE, Dasen SE, Edlind TD, Schidlow DV, Burns JL, et al. Ribotype analysis of Pseudomonas cepacia from cystic fibrosis treatment centres. $\mathcal{F}$ Pediatr 1988;113:859-62.

17 Smith DL, Smith EG, Gumery LB, Stableforth DE. Pseudomonas cepacia infection in cystic fibrosis. Lancet 1992;339:252.

18 Govan JRW, Brown PH, Maddison J, Doherty CJ, Nelson JW, Dodd M, et al. Evidence for transmission of Pseudomonas cepacia by social transmission in cystic fibrosis. Lancet 1993;342:15-9.

19 Millar-Jones L, Paull A, Saunders Z, Goodchild MC. Transmission of Pseudomonas cepacia amongst cystic fibrosis patients. Lancet 1992;340:491.

20 Smyth A, Heaf D, Corkill J, Hart T, Sisson P, Freeman R. Transmission of Pseudomonas cepacia by social contact in cystic fibrosis. Lancet 1993;342:434-5.

21 Smith DL, Gumery LB, Smith EG, Stableforth DE, Kaufmann ME, Pitt TL. An epidemic of Pseudomonas cepacia in an adult cystic fibrosis unit: evidence of person-to-person transmission. $f$ Clin Microbiol evidence of persc

22 Gladman G, Conner PJ, Williams RF, David TJ. Controlled study of Pseudomonas cepacia and Pseudomonas maltophilia in cystic fibrosis. Arch Pseudomonas cepacia and Pseudomonas maltophilia in cystic fibrosis. Arch

23 CF Trust Ps cepacia Working Group Cystic fibrosis statement of Pseudomonas cepacia. Association of Cystic Fibrosis Adults (ACFA) Newsletter 1993;December:2-5.

24 Doring G, Schaffer L, eds. Epidemiology of pulmonary infections by pseudomonas in patients with cystic fibrosis: a consensus report. French Cystic Fibrosis Association, 1993.

25 Walters S, Smith EG. Pseudomonas cepacia in cystic fibrosis: transmissibility and its implications. Lancet 1993;342:3-4.

26 Tablan OC, Carson LA, Cusick LB, Bland LA, Martone WJ, Jarvis WR. Laboratory proficiency test results on using selective media for isolating Laboratory proficiency test results on using selective media for isolating
Pseudomonas cepacia from simulated sputum specimens of patients with cystic fibrosis. $\mathcal{f}$ Clin Microbiol 1987;25:485-7. 